\title{
FLEXURAL BEHAVIOUR OF R.C BEAMS BY PARTIAL REPLACEMENT OF NATURAL SAND WITH FOUNDRY SAND
}

\author{
Satish S V' ${ }^{1}$, Shashi Kumar A ${ }^{2}$, G.Narayana ${ }^{3}$ \\ ${ }^{1}$ Post Graduate Student, Department of Civil Engineering, SJCIT, Karnataka, India \\ ${ }^{2}$ Assistant Professor, Department of Civil Engineering, SJCIT, Karnataka, India \\ ${ }^{3}$ Head of the Department, Department of Civil Engineering, SJCIT, Karnataka, India
}

\begin{abstract}
Metal foundries comprise of huge measure of sand as a piece of metal throwing procedure. It is vital to create gainful building materials from foundry sand. The natural sand has been replaced by foundry sand appropriately in the scope of $0 \%$, 15\%, and $25 \%$ by weight for M-4o evaluation concrete. Concrete blends were delivered, tested and analyzed in properties for 7,14 , \& 28 days. Subsequently, compressive strength expanded up to $25 \%$ expansion of foundry sand and at $35 \%$ substitution level the compressive quality diminished progressively. Hence the beams were casted with $25 \%$ foundry sand. The flexural strength has been determined at the end of 28 days. Keeping this view, the point of examination is the flexural conduct of R.C beams by partially replacing common natural sand with foundry sand.
\end{abstract}

Keywords: Foundry sand, natural sand, compressive strength, flexural strength.

\section{INTRODUCTION}

Most metal throwing sand comprises of good silica sand with uniform physical qualities. Foundry sand is the side effect of ferrous and non-ferrous metal throwing industry. In present day foundry practice, sand is commonly reused and reused through numerous generation cycles. Foundry sand can be utilized as a part of cement to enhance its quality and strength components. Foundry sand can be utilized as a halfway or aggregate substitution of fine totals.

In foundry industry, the most well-known metal throwing procedure utilized is sand cast framework. All sand cast molds for ferrous castings are of green sand sort. Green sand comprises of superb silica sand, around $10 \%$ of bentonite mud, $2-5 \%$ of water and around $5 \%$ of ocean coal. Notwithstanding green sand molds, synthetically fortified sand cast frameworks are additionally utilized.

There are pretty nearly 4500 units of foundry in India; out of which $80 \%$ are little scale units and $10 \%$ are medium and vast scale units. Foundry industry gauges that more or less 100 million tons of sand is utilized as a part of generation yearly and 6-10 million tons tossed every year.

Some foundry industries blaze their sludge in incinerators, adding to genuine air contamination issues. To diminish transfer and contamination issues from these mechanical squanders, it is key to create beneficial building materials.

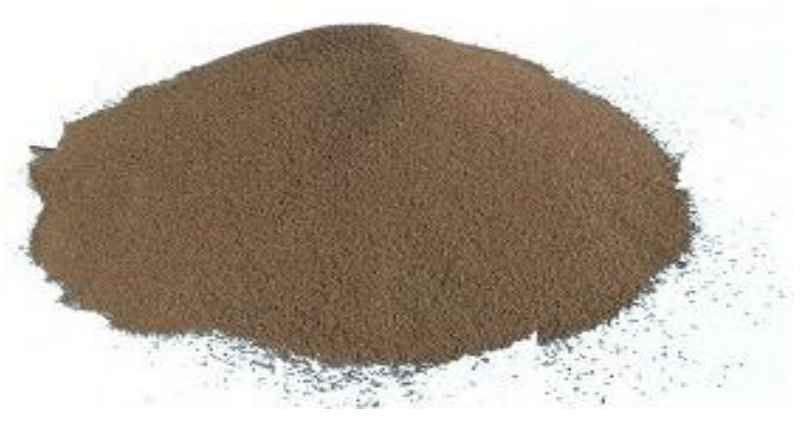

\section{EXPERIMENTAL INVESTIGATION}

\subsection{Materials}

The materials utilized as a part of the blend outline were Ordinary Portland Cement (OPC), natural sand, foundry sand and consumable water. Shaft examples were made with M-40 evaluation concrete. Water/Cement proportion of 0.42 and $0.6 \%$ of ConplastSP430 super plasticizer was utilized for better workability. Fe 500 evaluation steel was utilized for longitudinal support and stirrups.

\subsection{Preliminary Investigation}

Cube examples were cast with and without foundry sand on the mold of size $150 * 150 * 150 \mathrm{~mm}$ for each 1:1.63:2.32 Solid Blend. After around $24 \mathrm{hrs}$ the $3 \mathrm{D}$ cube examples were de-formed and water curing was done till the separate examples were tried following 7, 14, and 28 days for compressive quality. Compressive strength of blends at distinctive curing time of 7 days, 14 days and 28 days quality of blends with $0 \%, 15 \%, 25 \%$ and $35 \%$ were tried. At $15 \%$ and $25 \%$ the compressive quality of cement with 
foundry sand was more than the standard solid examples when tried at 28 days. However, for $35 \%$ replacement with foundry sand there was steady diminishing in the compressive quality of cement. Subsequently beam examples were cast with $25 \%$ foundry sand.

\subsection{Reinforcement Details}

Eight numbers of beams were casted with and without foundry sand. The span of the beam was $2000 \mathrm{~mm}$ and of size $150 \mathrm{~mm} \times 250 \mathrm{~mm}$. Out of 8 beams 4 were cast without foundry sand and four were cast with $25 \%$ foundry sand as replacement for natural sand. All specimens were tested at $28^{\text {th }}$ day from the date of casting. Reinforcement details of beam specimens are shown in Table-1.

Table-1: Reinforcement Details

\begin{tabular}{|c|c|c|c|c|c|c|}
\hline \multirow{3}{*}{$\begin{array}{l}\text { Sl. } \\
\text { No }\end{array}$} & \multirow{3}{*}{ Beams } & \multirow{3}{*}{$\begin{array}{l}\text { Testing } \\
\text { date } \\
\text { (Days) }\end{array}$} & \multicolumn{4}{|c|}{ Reinforcement in beams } \\
\hline & & & \multicolumn{2}{|c|}{ Longitudinal } & \multicolumn{2}{|c|}{ Stirrups(mm) } \\
\hline & & & Top & Bottom & Dia. & spacing \\
\hline 1 & NCC1 & \multirow{8}{*}{$\begin{array}{l}28 \\
\text { Days }\end{array}$} & 2\#8 & $2 \# 12$ & 8 & 165 \\
\hline 2 & NCC2 & & $2 \# 8$ & $2 \# 12$ & 8 & 165 \\
\hline 3 & NCC3 & & 2\#8 & 2\#16 & 8 & 165 \\
\hline 4 & NCC4 & & $2 \# 8$ & 2\#16 & 8 & 165 \\
\hline 5 & FSR1 & & $2 \# 8$ & $2 \# 12$ & 8 & 165 \\
\hline 6 & FSR2 & & $2 \# 8$ & $2 \# 12$ & 8 & 165 \\
\hline 7 & FSR3 & & $2 \# 8$ & $2 \# 16$ & 8 & 165 \\
\hline 8 & FSR4 & & $2 \# 8$ & $2 \# 16$ & 8 & 165 \\
\hline
\end{tabular}

NCC=Normal Conventional Concrete, FSR=Foundry Sand Replacement $(25 \%)$

\subsection{Test Set-Up}

The beam examples were tested by utilizing stacking casing (Loading Frame) of 100T limit under two point loading system. All the beam examples were white washed to encourage checking of breaks. The heap was connected statically orderly to the shaft. The pillars were instrumented with linear voltage displacement transducers (LVDTs). All the deflection readings were recorded naturally utilizing data logger amid the test.

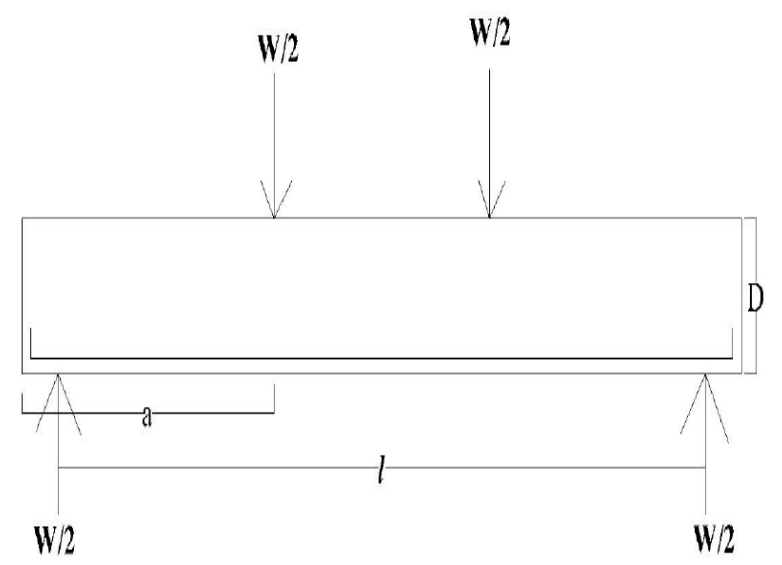

Fig-1: Two point loading system

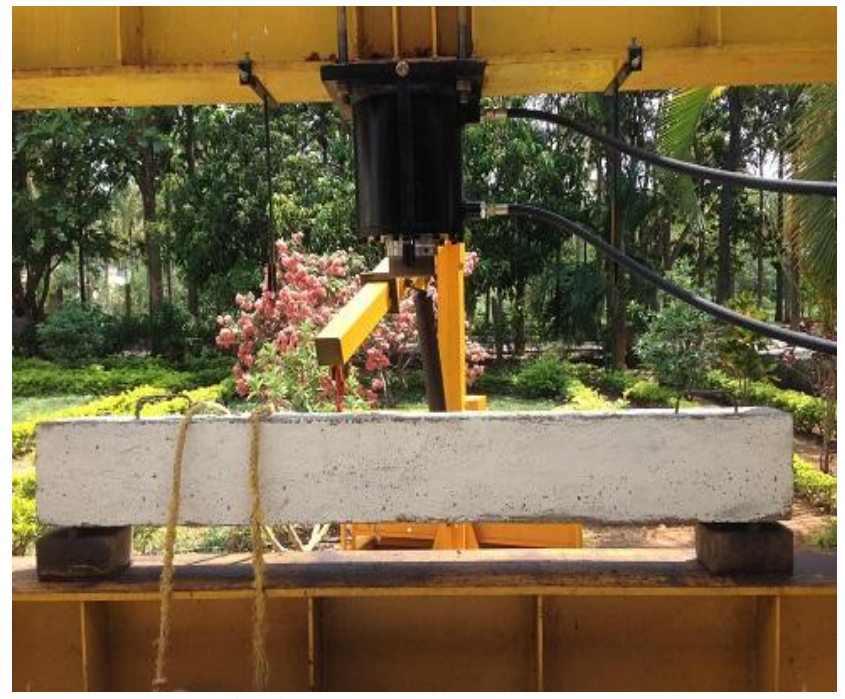

Fig-2: Test set-up of the Beam

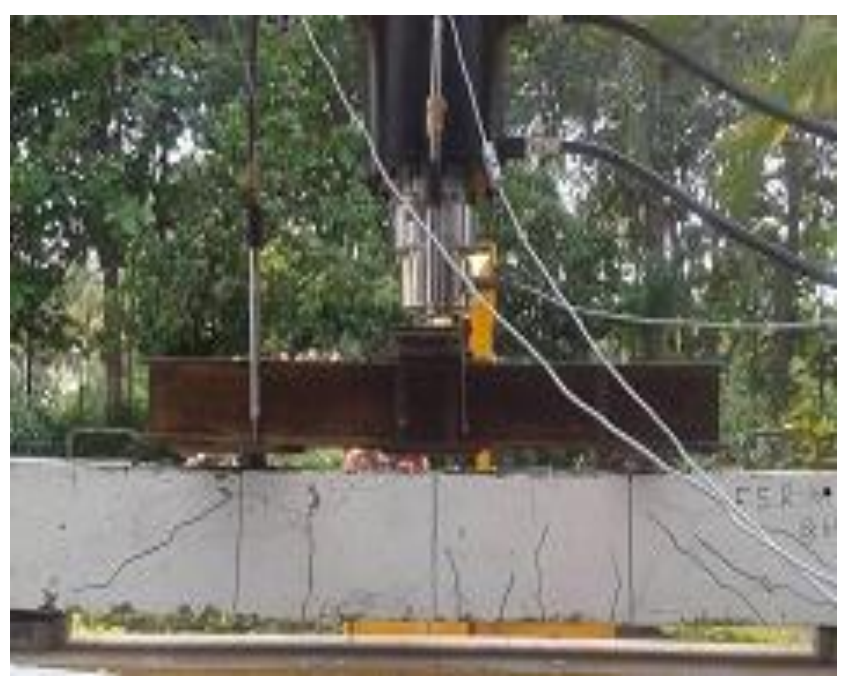

Fig-3: Failure of the Beam

\section{EXPERIMENTAL RESULTS}

Table-2: Results

\begin{tabular}{|c|c|c|c|c|}
\hline Sl.No & $\begin{array}{l}\text { Beam } \\
\text { Designation }\end{array}$ & $\begin{array}{l}\text { Cracking } \\
\text { Load in } \\
\mathrm{kN}\end{array}$ & $\begin{array}{l}\text { Average } \\
\text { Cracking } \\
\text { Load in } \\
\mathrm{kN}\end{array}$ & $\begin{array}{l}\text { Ultimate } \\
\text { Failure } \\
\text { Load in } \\
\mathrm{kN}\end{array}$ \\
\hline 1 & NCC1 & 60 & \multirow{2}{*}{62.25} & 95 \\
\hline 2 & NCC2 & 64.5 & & 103 \\
\hline 3 & NCC3 & 85 & \multirow{2}{*}{82.5} & 152.5 \\
\hline 4 & NCC4 & 80 & & 149.5 \\
\hline 5 & FSR1 & 102.5 & \multirow{2}{*}{103.25} & 107 \\
\hline 6 & FSR2 & 104 & & 110 \\
\hline 7 & FSR3 & 107 & \multirow{2}{*}{108.5} & 161.7 \\
\hline 8 & FSR4 & 110 & & 170 \\
\hline
\end{tabular}




\section{COMPARISION OF RESULTS}

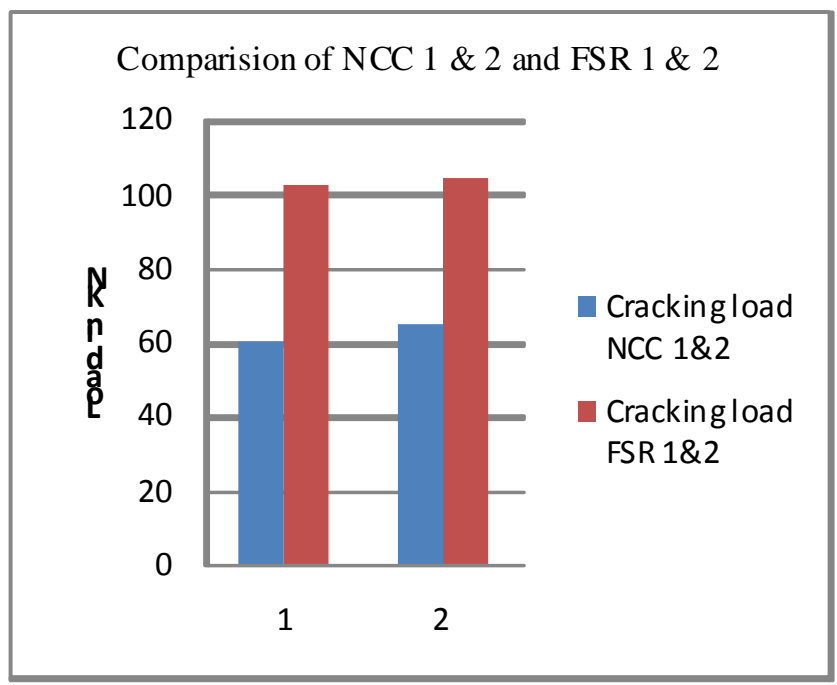

Chart -1: Comparision of NCC $1 \& 2$ and FSR 1 and 2

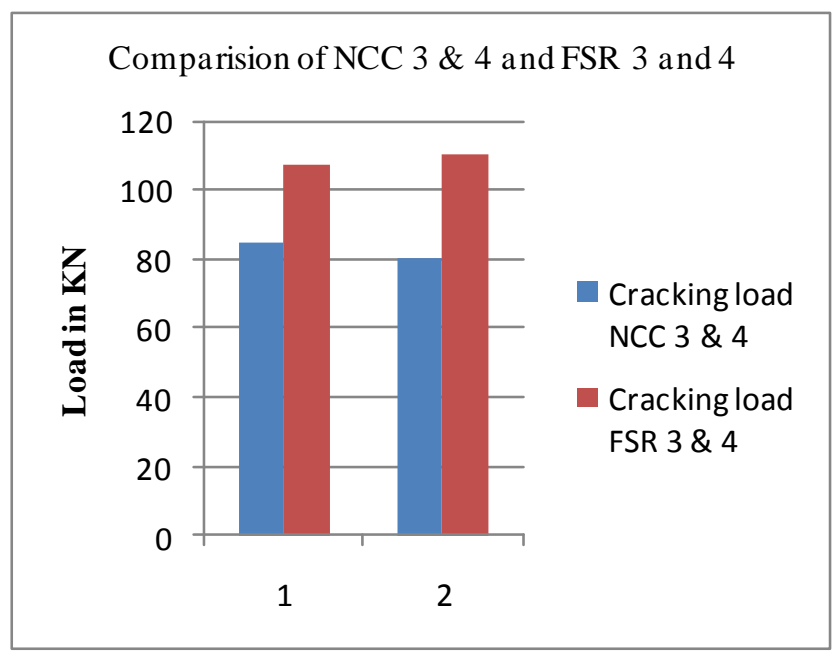

Chart -2: Comparision of NCC $3 \& 4$ and FSR 3 and 4

\section{CONCLUSION}

Based on the above experimental results, we can conclude that

1. The beam specimens with foundry sand (FSR) has higher Flexural strength than the Normal Conventional Concrete (NCC) beam specimens.

2. $25 \%$ of Flexural strength was increased as compared to Conventional Concrete.

\section{REFERENCES}

[1]. Abichou T Benson, C Edil, Database on Gainful Reuse of Foundry Side effects, Reused Materials in Geotechnical Applications Geotech. ASCE, Spec. Publ., 79, 1992, 210 22

[2]. D. Pradeep Kumar, Dr. P. Eswaramoorthi, Basil Child, Quality Attributes of Basic Solid Components Utilizing Foundry Sand, Worldwide Diary of Designing Exploration and Applications (IJERA), ISSN: 2248-9622
[3]. T R Naik, Kraus, N. Rudolph, Chun Yoonmoon, Ramme, W. Bruce and SiddiqueRafat, Precast Solid Items Utilizing Modern By-Items, ACI Materials Diary, 101 (3), 2004, 199- 206.

[4]. Pathariya Saraswati C, Rana Jaykrushna K, Shah Palas A , Mehta Jay G , Assistant Prof.Patel Ankit N. "Use of Waste Foundry Sand for Evolution of Low - Cost Concrete".Global Journal of Engineering Trends and Technology (IJETT). V4 (10):4281-4286 Oct 2013. ISSN: 2231-5381.www.ijettjournal.org.distributed by seventh sense examination bunch.

[5]. Eknath P. Salokhe, D.B.Desai, "Application o f Foundry Waste Sand in Manufacture of Concrete". Kolhapur, India. [6]. Tikalsky, J. Paul, Smith, Earl, Regan and W. Raymond, Properties of Controlled Low Quality Materials Containing Foundry Sand, ACI Material Journal, 97, 2000, 698- 702.

[7]. T R Naik and S Singh, Permeability of Flowable Slurry Materials Containing Foundry Sand and Fly Ash, Journal Of Geotechnical and Geoenvironmental Designing ASCE, 123(5), 1997, 446-452.

\section{BIOGRAPHIES}

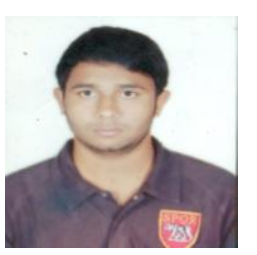

Mr.Satish S V, Pursuing Final Year Mtech in Structural Engineering in SJC institute of Technology, Chickballapur.

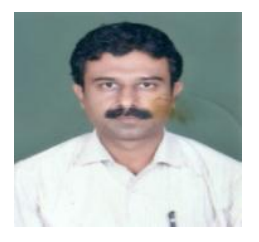

Mr.Shashi Kumar. A, Assistant Professor, Department of Civil Engineering, SJC institute of Technology, Chickballapur. He has wide experience in teaching field for over 15 years and currently pursuing his Ph.D.

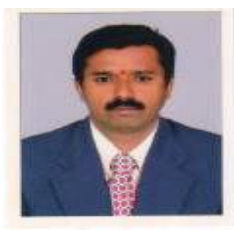

Dr.G.Narayana, Professor and Head of Civil Engineering Department, SJC institute of Technology, Chickballapur, have a wide experience in teaching and research in Structural Engineering field. $\mathrm{He}$ is also a Structural Designer and Consultant for many Projects. 